\title{
Article
}

\section{Engaging with Play and Graduate Writing Development}

Brittany Amell 1

School of Linguistics and Language Studies, Carleton University

Eve-Marie C. Blouin-Hudon

Department of Psychology, Carleton University

\section{Abstract}

We begin by situating this work and ourselves in graduate writing. Although our experiences as burgeoning researchers are not a focus of this article, we are nonetheless present in the background, not unlike a palimpsest. We trace one aspect of this palimpsest-the use of playful and creative methods to generate ideas for this paper-before then suggesting three key concepts we consider foundational to discussions about play and graduate writing development. These are play, playspace, and mindsets. Building on these concepts, we offer some concluding remarks about the ambivalence some learners may have-which we refer to as play ambivalence-and propose that this ambivalence is partly related to the three concepts underscored in this article. We suggest that future research in play and graduate writing development could better consider this play ambivalence.

Nous commençons cet article en situant ce travail en relief à qui nous sommes comme écrivains et étudiants gradués. Dans cet article, nous suggérons trois concepts clés aux concepts de jeu et de rédaction académique au niveau des études supérieures : la définition courante du jeu, que nous conceptualisons en tant qu'orientation où approche qu'une personne, la notion d'espace de jeu, et les théories implicites de l'intelligence et de la personnalité (e'e.g., mentalités). Bref, nous suggérons que la recherche future dans le cadre du jeu et de la rédaction au niveau gradué devrait mieux considérer les attitudes et la résistance contre le jeu. Nous proposons que cette ambivalence soit liée en part aux trois concepts que nous surlignons dans cet article. 


\section{Introduction}

The highest form of research [is] play.

-N.V. Scarfe

Play has been a subject of study in various fields for some time, but the implications that it has for supporting the writing and research development of academics continues to generate much resistance in academia mainly because it is perceived as unconventional, and because scholars do not fully understand its implications (Janks, 2012). Despite this, researchers are persevering, perhaps because the benefits of play are enticing. Play may facilitate the development of language, knowledge, and identity (Bergen, 2015; Tanis, 2012), and individuals who score higher on the personality trait of playfulness experience greater academic success (Proyer, 2011), demonstrate more innovative behaviour at work, report greater work satisfaction (Glynn \& Webster, 1992; Yu, Chen, \& Lin, 2007), cope more efficiently with stress (Barnett, 2012; Magnuson \& Barnett, 2013; Qian \& Yarnal, 2011), and report greater quality of life and satisfaction (Proyer, 2012, 2013; Proyer, Ruch, \& Müller, 2010).

Researchers may also be persevering because the implications that multi-modal, playful activities have for writing and research development are inspiring. As it relates to writing and research development for instance, some research suggests that playful activities might be best used to support conceptual thinking about the research and writing process (Badenhorst, Moloney, Rosales, \& Dyer, 2016). In a similar vein, other work suggests that visual activities can support problem solving, reflection, and metacognition (Peabody \& Noyes, 2016; Simmons \& Daley, 2013). In fact, a growing number of researchers are considering the implications of multi-modal, playful activities from a variety of perspectives, such as a methodological perspective (e.g., arts-based research), a writing development perspective (Badenhorst, et al., 2016), and from an academic development perspective (Simmons \& Daley, 2013).

In this special section of the Canadian Journal for Studies in Discourse and Writing/Rédactologie, scholars do some important work in describing and relating their approaches to developing playful and innovative thinking about research and writing development. Crucial to these conversations is 
a shared understanding of-as we suggest in this paper-at least three interrelated concepts: play, playspace, and implicit theories of personality (a.k.a. "mindset"). These concepts speak not only to the activity (play), but to the environment (playspace), and the individual (mindset). Rather than suggest these concepts definitively, we take a collaborative, working approach to them-offering them to readers as starting points for critical engagement and cultivation, encouraging what we hope will be a fruitful discussion that will contribute to further development of this burgeoning area of research.

Drawing on the literature on play from fields such as education, psychology, and organizational psychology, we suggest a working definition of play that researchers can use to frame their approaches to play and graduate writing development. Practitioners may also appreciate a working definition that they can offer graduate students who participate in their courses or workshops and may not understand what is meant by the term "play." Next, we bring forward the notion of playspace (after Meyer, 2012), which we adapt for use with graduate students by incorporating a consideration of contact zones (Pratt, 1998), liminal spaces (Meyer \& Land, 2006; Turner, 1982), and safe houses (Pratt, 1998). In this paper, we explore a few reasons why we posit that the notion of playspace should include contact zones, liminal spaces, and safe houses. Then, we move from a consideration of space to the individual, drawing on the concept of what is colloquially referred to as "mindset," but formally known as implicit theories of personality and intelligence (Dweck \& Leggett, 1988; Henderson \& Dweck, 1990). Building on these concepts of play, playspace, and mindset, we offer some concluding remarks about the ambivalence some learners may havewhich we refer to as "play ambivalence." We suggest that future research in the area of play and graduate writing development could better consider the attitudes and resistance toward play, and propose that this ambivalence is related in part to the three concepts we underscore in this article.

Before we jump into a discussion of play, playspace, and mindset, however, we find it useful to unpack the portmanteau of "writing." Writing and research occupies a critical role in graduate education, with more students under intensified pressure to publish and complete degrees in a timely manner (Aitchinson, Kamler, \& Lee, 2010; Cotterall, 2011; Maher et al., 2008). Yet, both writing and research are often downplayed in terms of their value, complexity, and difficulty (Badenhorst, Moloney, Rosales, \& Dyer, 2012; Kamler \& Thomson, 2006). At the same time, writing and research are two interwoven processes that cannot be separated ${ }^{2}$ (Aitchison \& Lee, 2006; Kamler \& Thomson, 2006; Paré, 2011). For instance, concerns about the research process are often questions about translating ideas into writing (Aitchison \& Lee, 2006; Paré, 2011). In addition, 
Volume 28, 2018

http://journals.sfu.ca/cjsdw

graduate writing and research are both challenging and complex cognitive and linguistic tasksstudents must learn to negotiate the complexities of academic writing, while addressing questions about the writing and research process, as well as about identity and disciplinary textual practice(s) (Aitchison \& Lee, 2006). Both play and writing can act as heuristic strategies to understand what it is that we think, mean, or know (Paré, 2009; Melamed, 1985); unfortunately, it seems that students seek support only when issues with their writing or language arise-referred to as a "crisis control" model of writing (Aitchison \& Lee, 2006).

Perhaps it is at this point that we introduce ourselves. We are uniquely positioned as graduate (doctoral) students, writers, and researchers with a mutual interest in play and imagination. Brittany is studying applied linguistics and discourse studies at Carleton University and her interests include the use of playful and visual methods for supporting graduate writing development. Eve-Marie is studying psychology at Carleton University and has an interest in the implications that imagination and daydreaming might have for the future selves of students. While we both describe our relationships with our writing to be fairly positive, we nonetheless find ourselves identifying with many of the struggles we previously identified. Writing occupies a crucial role in our lives-it is one of the chief ways our value as potential academics is assessed, and at times it serves as a powerful gatekeeper that grants us permission to continue with our studies and research (e.g., comprehensive examinations, research proposals, scholarship applications). For this paper, at least one of us-Brittany-confronted questions about her writing that touched on larger, intricate issues of researcher identity, purpose, and direction. Both of us understand firsthand how questions and challenges with writing can also be challenges with language or a lack thereof, which is why we particularly appreciated adopting play as a strategy for developing this paper. And while this paper is not intended to be auto-biographical, of course it is in some way-how can we write about graduate students and their writing without identifying in some ways with what we are writing about? To be sure, this paper does not foreground our attempts to understand ourselves, our writing, or our positionalities as burgeoning researchers, but nonetheless we are there in the background and the blueprint of this paper, not unlike a palimpsest ${ }^{3}$. In the next section, we trace one aspect of this palimpsest: our use of playful and creative methods to brainstorm ideas for this paper. 


\section{Glimpsing the palimpsest: Two activities and the genesis of this paper}

Though we both were excited about the potential that writing a paper on play and graduate writing could have, like many writers who struggle with beginning, we too were uncertain as to the topic of our paper. In this section, we share two playful activities we used as strategies to generate ideas for this paper-one created by Eve-Marie that used imagination, and one developed by Brittany that relied on the use of collages. We share these activities for three reasons. First, these activities may helpful to those who are interested in experimenting with playful approaches to their own writing. Second, by allowing readers to catch a glimpse behind the scenes-at the vestiges of our early texts-we situate ourselves as writers and as practitioners. Third, although experienced writers understand that their pieces evolve, as graduate students we feel there is value in sharing the genesis of our paper to support efforts that try to demystify the process(es) of writing. Although neither of us can clearly articulate exactly how, these activities unexpectedly led us to question our assumption about the usefulness of play, and explore some possible scenarios in which play might not be useful. This was key for us: we had to let go of the outcome of the play activities and instead follow the process.

For the first activity, we generated a list of eighteen words related to writing, creativity, and play. This list contained both positive and negative words related to these broad themes, such as 'performance,' 'failure,' 'silly,' and 'make believe.' To begin, we found somewhere quiet and comfortable to sit for 60 to 70 minutes, and removed any distractions from our environment (for example, phone, other people, pets). We then set eight timers at pre-determined intervals (for example, at five, eight, fifteen, twenty, twenty-four, twenty-six, thirty-two, and forty minutes). Once these timers were set, we read the list of words and began the exercise. To do this, we closed our eyes and let our minds wander. When the first timer rang, we recorded what was going through our minds using a recording device. We could say keywords or elaborate on more detailed descriptions. The most important element was that our thoughts were recorded quickly and efficiently after the timer rang. We repeated this exercise until all eight timers had elapsed. The ultimate goal with this activity was to prime ourselves-using the list of words-into spontaneously thinking about writing, play, and creativity. We wanted to see how we could better understand these themes by seeing how they spontaneously associated in our minds as we relaxed. This activity taught us that a lot of insecurities and resistance about writing happens below our awareness. As such, becoming aware of our thoughts about writing helped us better understand the barriers that may slow down 
Volume 28, 2018

http://journals.sfu.ca/cjsdw

or hinder our writing and the process of generating and incubating ideas. Ultimately, fostering this awareness allowed us to take a step back from our own preconceptions about writing and to clearly and freely speak to the experience of writing within play.

Approximately a week and a half later, we engaged in the second activity. We set aside 60 minutes to visually-via cut and paste paper collaging-respond to the question of "what don't we want this paper to be (about)?" At this point, neither of us knew what the paper was going to be about, asides from the general topic of play and graduate writing (as outlined in the call). We opted to record our thoughts during the process of collaging. In this way, we adopted a version of a thinkaloud-protocol (Fonteyn, Kuipers, \& Grobe, 1993). After we finished our collage, we wrote brief reflective memos and shared our experiences with each other. The collages appear in Figures 1 and 2.

Though we used these activities as (generative) invention strategies for this paper, Brittany has previously used college responses to narrow and focus sections of her writing, as well as a strategy to clarify her conceptualisations of her research. Using techniques such as the collage response may be useful to students who find it difficult to articulate their ideas, who are working through a problem, or who are struggling with finding direction. The list of question stems (see Appendix) may prove to be useful for those who are interested in using collage in their own work. In the sections that follow, we return to the focus of this article: unpacking the three interrelated concepts of play, playspace, and mindset. We then turn to a consideration of the ambivalence that some students may experience towards play, suggesting that this ambivalence relates in part to the three concepts we underscore in this article.

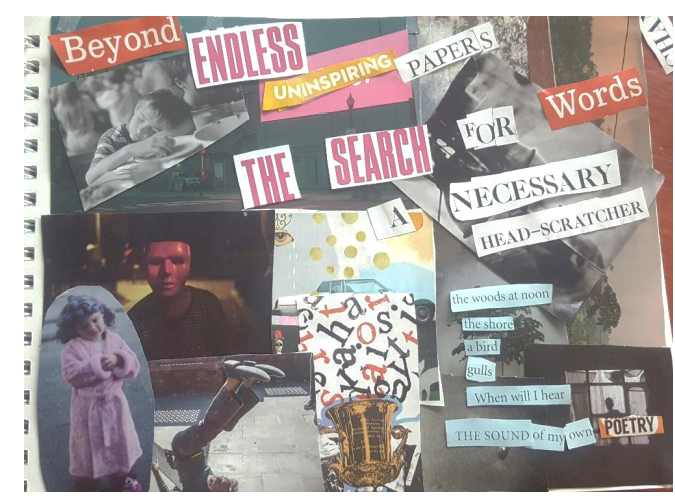

Figure 1. Brittany's Collage: What don't I want this paper to be (about)? 
Volume 28, 2018

http://journals.sfu.ca/cjsdw

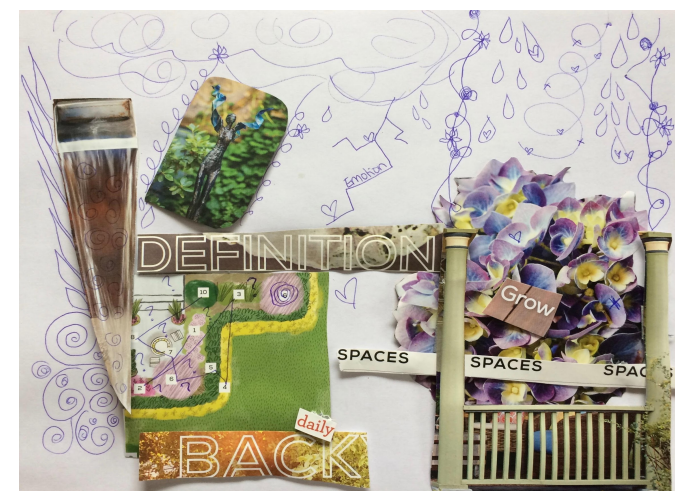

Figure 2. Eve-Marie's Collage: What don't I want this paper to be (about)?

\section{Play}

You don't stop playing as you grow old, you grow old because you stop playing.

-George Bernard Shaw

Multiple definitions of play describe it as a humorous or entertaining activity that is intrinsically motivated and accompanied by feelings of well-being (Barnett, 2007; Henricks, 2014; Statler, Heracleous \& Jacobs, 2011; Sutton-Smith, 1997). Play may also incorporate elements of surprise, spontaneity, and self-awareness, as well as embodied learning-that is, learning located at the level of the body (Tanis, 2012). Common to definitions of play is a focus on the player and their fun, relaxation, or escape. Although the term "serious play" has been employed to describe the instances where play and work are "deliberately and meaningfully juxtaposed" to accomplish work-related goals (Statler et al., 2011, pp. 239-240), some researchers suggest that play can go beyond the types of tasks or activities in which one engages. These researchers suggest that "play" can refer to the orientation or approach one takes to the activity (Sutton-Smith, 1997; West, Hoff, \& Carlsson, 2016). In other words, "just about any activity, including those we do everyday at work, can-with a playful approach-be transformed into play...[even a] corporate email” (West, et al., p. 72). This definition of play - that is, the orientation or approach that one takes to the tasks at hand-seems particularly applicable to the context of graduate student writing and it is the one we take in this paper. 
Volume 28, 2018

http://journals.sfu.ca/cjsdw

While some play activities might thrive on a lack of mastery, at other times the skills of the individual may match the difficulty or challenge imposed by the play activity, which can give rise to flow-a state of mind underlined by optimal concentration, engagement, and sense of accomplishment (Csikszentmihalyi, 1991; Vygotsky, 1978). Some play activities, such as imaginary play or video-gaming, may also allow individuals to temporarily step outside of their immediate circumstances and related constraints to bend, flex, defy, evade, or even rebel against circumstances that are otherwise beyond their control (Miller, 2013; Singer \& Singer, 1990; SuttonSmith, 2008; Sutton-Smith \& Kelly-Byrne, 1984).

Though we have known for some time that writers often rely on imagination to invent their audiences (Bartholomae, 1986), play may allow for and encourage an engagement with the performances of the self/other in unconventional, yet strategic ways (Henricks, 2014; James, 1890). For instance, in my workshops with doctoral students, I (Brittany) asked workshop participants to consider the following question:

Imagine your research question is a celebrity and the theories, key concepts, methods (etc.) form the entourage. Who (participants, theorists, etc.) or what (key concepts, research puzzle, etc.) is in the room with the celebrity?

This question asks workshop participants to imagine the key pieces in their research puzzles and, at the same time, practice communicating their response to an audience (other workshop participants) who typically were not familiar with their research or their field. Other researchers (e.g. Badenhorst, Moloney, Dyer, Rosales, \& Murray, 2015) have used poetry as a way to encourage students/researchers to re-imagine their writing, and thus aspects of their self, from a different angle. Some participants reported that the workshops shifted their relationship to their work in new and surprising ways. In the case of Badenhorst et al. (2015), play was used to support writing/research development and, at the same time, shed light on the situated and contested nature of academic writing — consistent with an academic literacies approach (Lillis \& Scott, 2007).

As noted earlier, play can encourage individuals to step out of their comfort zone and push against perceived limitations or challenges using existing or new skills (Tanis, 2012). In the context of writing development, play may provide students with opportunities to challenge and overcome obstacles in their writing or research-conceptual or otherwise. Students may also find that play 
Volume 28, 2018

http://journals.sfu.ca/cjsdw

also opens up space to engage with the process of shedding and re-envisaging their thinking about their writing and research, as well as their thinking about themselves (for example, the writing self), thereby developing new ways of thinking and engaging with their research and writing. However, in order to engage in this thinking and re-imagining, students need to be provided with a sense of safety. In the next section, we propose that this space-the playspace-can be bounded enough to provide a sense of safety if they are intentionally crafted as sites of equality, trust, and protection.

\section{Introducing "playspace"}

One of the reasons play may facilitate the development of language, knowledge, and identity (Bergen, 2015; Tanis, 2012) may be related to the space we have, in play, to explore "our selves and our society" (Silverstone, 1999, as quoted in van Leeuwen \& Westwood, 2008, p. 159). The concept of space has already been tied to writing and writing classrooms (e.g. Nagelhout \& Rutz, 2004), as well as to play ("playspaces", after Meyer, 2012). And while the implications that play can have for graduate writing development has been a focus of some research, few if any scholars speak to the spaces where play is used to support graduate writing in an academic setting. Meyer's (2012) notion of playspace-the "space quite literally for the play of new ideas, for people to play new roles, for more play in the system, and for improvised play" (p. 26) - is a useful concept to build on to, but more work needs to be done by scholars to adequately and critically investigate the ways in which multiple and diversely asymmetrical relations of power ("contact zones", after Pratt, 1998) are obscured and or manifested in the academic spaces where play occurs. Different cultures of thought, but also of backgrounds, meet in the halls and on the pages to contend with and negotiate knowledge, identity, and power (Pratt, 1998). Pratt's (1998) notion of the contact zone is one place to begin, but ultimately a critical approach to the concept of playspace can and should draw on broader critiques of the systemic barriers that many students grapple with while negotiating their academic careers.

Also, supports for writing-if offered at all-are often marginalised within the university (Aitchison \& Lee, 2006; Badenhorst et al., 2012), offered as an ad-hoc response that is downloaded onto "writing experts" or, in the case of Brittany, other graduate students. Either way, if supports are segregated, the onus is on students to step outside of the supervisory relationship to access these supports. This, especially when coupled with an attitude toward writing as a transferable skill 
Volume 28, 2018

http://journals.sfu.ca/cjsdw

that one must simply acquire (Lea \& Street, 1998), not only obfuscates the complexity that writing entails but has important ramifications for the playspace. One important ramification is the usage of play runs the risk of becoming, much like the teaching of writing across campuses in the U.S. and to some extent in Canada, decontextualized and offered as a one-size-fits-all quick fix (see Downs \& Wardle, 2007, for their discussion of the teaching of writing in the U.S.). To be clear, we do not mean to suggest that this is an inevitable reality. Instead, we highlight the importance of taking a hopeful and balanced approach to the use of play, while also considering the broader contexts that play takes place within.

Related to a consideration of playspace, but in a different vein from that of contact zones and segregated supports, is the notion of liminality and liminal spaces. Liminal spaces can refer to material or immaterial transitional spaces that one travels through prior to the crossing of a conceptual threshold (Meyer \& Land, 2006). They are often described as murky, ambiguous, and confusing (Meyer \& Land, 2006; Savin-Baden, 2008; Trafford \& Leshem, 2009). They are also described as being especially uncomfortable, likely because one's movement through them often occurs in a spontaneous, non-linear, or otherwise unpredictable fashion (Keefer, 2015; Kiley, 2009). The result can be intense periods of discomfort, 'stuckness,' befuddlement, and uncertainty about identity and purpose in life (Meyer \& Land, 2006; Savin-Baden, 2008). These transitional spaces can simultaneously become transformative spaces, provided that learning bridges are available to help students create links between where they are and the path they intend to take (Savin-Baden, 2008), and play may be one such learning bridge. However, graduate students may also temporarily find themselves thrust into liminal spaces via the fluid and spontaneous nature of play.

One upshot of the playspace may be its bounded nature (e.g., that play occurs for a period of time and in a particular setting). This bounded nature may provide a sense of safety for exploring and navigating one's own liminality as it relates to their learning. But this safety may only be experienced if playspaces are intentionally crafted as sites where students can meet with other students while maintaining a sense of equality, trust, and protection from legacies of oppressionsafe houses, after Pratt (1998). If play can occur in spaces that feel safe and non-threatening, students may be more comfortable engaging with their vulnerabilities and as such, free to tap into all layers of self-experience (Bird \& Reese, 2008; Damasio, 2010; Moore \& Barresi, 2013) without fear, anxieties, or expectations (Davies Turner \& Turner, 2015). Rather than attempting to replicate the work already done by other scholars on creating safe learning spaces, we suggest interested 
readers engage with the substantial resources available. We started with our campus teaching and learning centre and equity services centre. One suggestion we appreciated was that of a critically reflective practice whereby, through self-awareness, inquiry, and reflection, we not only reflect on our roles but adapt our teaching or facilitation style so that "power over" becomes "power with" students (Larrivee, 2000, p. 293). Another suggestion that we found helpful has been to devote time at the beginning of the session to develop some guidelines for behaviour, drawing on input from students-though how this is done depends, of course, on the context. Brittany uses a combination of both these suggestions in her practice, but also opens each session with a few moments of quiet time to breathe and collect oneself before acknowledging that her sessions take place on unceded Algonquin territory.

There are a few points to clarify before we move on. The first is that we see contact zones, liminality, and safe houses as embedded aspects of playspace, especially when in conjunction with graduate writing development. In addition, we see playspaces as blended spaces, that is, spaces that are material and immaterial, external and internal. We acknowledge that this ambiguity might frustrate some readers, however we are not the first to suggest this. Instead, this notion of space is derived from postmodern geographers who are increasingly considering blended spaces, and troubling notions of space as neutral, empirical, objective, and-perhaps more importantlymappable areas (Hubbard \& Kitchin, 2011). As Crang and Thrift (2000) notoriously note in the opening of their book: "space is the everywhere of modern thought" (p. 1). We argue that this concept of space is at once engaging, elusive, messy, practical, theoretical, frustrating, and worth it. Rather than fighting with the ambiguity and nebulousness of this view, we have embraced it as part of exploring the concept of space.

Second, and equally important we acknowledge that graduate student writing is precarious work and that, at the same time, the academic space is a contested one replete with systemic barriers. Students who feel a lack of supervisory, committee, or departmental support for their ideas (Jazvac-Martek, Chen, \& McAlpine, 2011) — or do not feel they belong to the culture in which they are studying, disciplinary or otherwise (Amell, 2016) - may also experience challenges with their writing and research that go beyond that of play and playspace. An important question that a future paper may consider is how graduate student writing can engage with the injustices and inequalities that are inevitably a part of the academic world, especially with an emphasis on the ways in which playspaces interface with broader social contexts. At the same time, we should not lose sight of graduate writers who are already doing some important work in engaging with and 
Volume 28, 2018

http://journals.sfu.ca/cjsdw

challenging the inequities of the academy. To do otherwise may contribute to the further marginalisation of these scholars, and unintentionally recenter those in power (LaRocque, 2015).

In the next section, we discuss the agency of individual vis-à-vis "mindsets" (that is, implicit theories of intelligence and personality), with the suggestion that these mindsets can interface with the playspace. Perhaps now is a good time to include an important caveat. Though we suggest that an awareness of mindset or implicit theories of personality and intelligence may be helpful for those who are interested in engaging graduate students in play, we are not suggesting that mindset alone will help students to overcome the systemic barriers they might encounter. Nonetheless, an understanding of "mindset," and not just the characteristics of the playspace itself, can have an important part in creating a fruitful play experience.

\section{Mindset}

In this section, we discuss what is commonly known as "mindset," but formally referred to as implicit theories of personality and intelligence (Dweck \& Leggett, 1988; Henderson \& Dweck, 1990). The notion of "implicit theories" refers to the beliefs that individuals hold about their own and other's ability to change. People can differ quite significantly when it comes to perceiving and interacting with the physical and social world, but the research literature we draw on mostly focuses on two overarching theories: entity (fixed) and incremental (growth) (Dweck, Chiu, \& Hong, 1995). An individual who holds an entity theory may explain their learning in terms of their perceived talent (or lack thereof), whereas one with an incremental theory might explain their learning in terms of their development or growth (Dweck \& Leggett, 1988; Henderson \& Dweck, 1990). Mindsets may influence on how individuals perceive themselves and interact with their external environment, such as when engaging in play activities. For example, mindsets may explain why some students may feel more comfortable with navigating the ambiguity of play spaces, whereas others may struggle. These mindsets may also suggest how and when people are more likely to pursue goals, such as writing a dissertation. For example, entity theorists may be more likely to engage in goals that are performance-based, while incremental theorists-on averagemay choose goals that will allow them to learn and improve their skills over time (Dweck et al., 1995).

An example of using play and mindset in an educational context can be found in research by 
O'Rourke, Haimovitz, Ballwebber, Dweck, and Popovic (2014). The goal of this study was to investigate whether teaching growth mindset strategies in the context of an educational game would influence persistence and effort in learning, while also making students more welcoming of challenges. To test their hypotheses, O'Rourke et al. (2014) assigned students to an educational puzzle game designed to develop skills in mathematics. In one version of the game, students were taught the growth mindset through the game's narrative, feedback, and rewards. In a second condition, students were only exposed to the game's original (and neutral) structure. To foster a growth mindset, the game highlighted that working hard-and even struggling—can work out the brain and make it better at solving problems later on. Furthermore, participants in this first condition received 'brain points' every time they used a new strategy to solve a puzzle in the game (that is, growth incentives).

Results of this study demonstrated that participants who were given growth mindset narratives and incentives changed the way that they approached new problems in the educational game over time. That is, these individuals used more flexible thinking when solving the game's puzzle over time than did participants who were not exposed to growth mindset strategies. Furthermore, participants who demonstrated more fixed mindsets benefited from the growth mindset training significantly more than individuals who already exhibited a highly flexible mind. Overall, these authors conclude that being exposed to games that foster a growth mindset can be useful in developing learning strategies that allow a person to persist in the face of challenges.

Research by Schmidt, Shumow, and Kackar-Cam (2016) supplements O'Rourke et al.'s (2014) findings by demonstrating how growth mindset interventions can transform students' learning experiences. In this study, students were either assigned to a growth mindset intervention, or to a content writing condition over a six-week period. Students assigned to the content writing condition were asked to write five sentences every Wednesday for six weeks about the science content that they were learning. Students assigned to the growth mindset condition were asked to complete a 50-minute long computer program called Brainology every Tuesday for six weeks. Brainology presented multi-media information about brain structure, function, and learning (for example, demonstrating how the brain is malleable, illustrating how practice can change the brain's neural paths, showing how certain learning techniques can help the brain grow, etc.). After learning this information, students were then required to complete games, puzzles, and quizzes that asked students to identify personal challenges, as well as their beliefs about fixed and growth mindsets as helping or hindering their learning. Students were also asked to reflect on the weekly computer 
Volume 28, 2018

http://journals.sfu.ca/cjsdw

tasks by filling out an e-journal embedded within the module.

Results of this study demonstrated that students in the growth mindset condition showed significant increases in perceived control and interest in their schoolwork over the six-week intervention period, and even demonstrated increases in skill and learning one year after the end of the intervention. To the contrary, students in the content writing condition actually experienced decreases in perceived control and interest for the duration of the experiment. This shows that fostering a growth mindset can help students overcome challenges by increasing their perceived control over their own learning, and by teaching them that performing less well on a particular task does not mean that they are unable to learn, but rather that they are in the process of growing their skills, and that takes time and consistent effort.

These findings are important in the context of play and graduate student writing because unexpected challenges arise at every step of the writing process. As such, play environments that also foster growth mindsets can help students handle writing setbacks by understanding that deep learning-in this case, of the writing process and of oneself as a writer-takes time and effort (Blackwell, Trzesniewski, \& Dweck, 2007; Dweck, 1999; Dweck, 2007). Play is a particularly relevant way to develop growth mindsets because these mindsets invite individuals to reframe challenges as fun and exciting, and to reframe progress as incremental, developing over time, rather than of performance (Blackwell et al., 2007; Dweck, 1999; Dweck, 2007). In a play environment, writers can be encouraged by teachers and facilitators to shed performance goals and to normalize challenges as a part of the process rather than as evidence of failure. At the same time, invoking a growth mindset and adopting a playful approach to writing invites writers to rethink what constitutes a 'normal' writing process, perhaps leaving space for new and creative insights to arise.

Although we suggest at least a consideration of mindset, there are important caveats to be acknowledged. In particular, one should take care to avoid sounding overly deterministic or superficial: implicit theories are malleable and respond to and are influenced by many factors such as the social environment, the teacher, and the state of the individual (for example, the degree to which they are aware of and seek to modify their thinking on a matter). Nonetheless, an understanding of mindsets can inform — at least partially—our pedagogical approaches. It might be useful to work with students toward building awareness of whether they explain their perceived success or failure in terms of a fixed ability or talent, or in terms of development (like a muscle). Educators may also support students with adopting an incremental theory of learning by reminding 
Volume 28, 2018

http://journals.sfu.ca/cjsdw

students that play is ambiguous and flexible, and because of this, can contribute to their growth in unexpected ways. It would make good pedagogical sense to scaffold play activities in a way that moved from less ambiguous and more structured, to more ambiguous and less structured.

\section{Some concluding remarks on ambivalence toward play}

Something that researchers and practitioners will no doubt come up against at one point or another is what we call "play ambivalence." We suggest that this ambivalence towards play may be related in part to the three concepts underscored in this article. First, graduate students may not understand what is meant by the term "play." They may see play as something that only children engage in, rather than the serious potential it may have as a strategy for coming to know (Melamed, 1985). Possibly related to this, play_like writing_might be mistakenly seen as separate from epistemological work (Paré, 2009; Melamed, 1985). Ambivalence toward play may also stem in part from a general socialised sentiment about play as an anathema to work (van Leeuwen \& Westwood, 2008). At the same time, researchers and educators can and should problematize this treatment of play. For instance, Turner (1982) suggests that it has only been relatively recently that "devotion to work" became a virtue and "play [became] the enemy of work" (Turner, 1982, p. 39). This positioning of play as opposite to or as a digression from work is evident in the variety of words adults use to describe play or playful activities (for example, leisure, a hobby, relaxing; van Leeuwen \& Westwood, 2008). However, researchers are beginning to suggest that the need for play persists over the lifetime-even if these needs are not understood or acknowledged (van Leeuwen \& Westwood, 2008). In other words, adults-even academics-continue to engage in play, but their play activities may look different. Perhaps then, taking time to frame the play activity by acknowledging and leaving space for play ambivalence is one approach we can take. Relatedly, framing the activity with a discussion of how one is defining play may be equally useful. Brittany embeds the definition she adopts (for example, play as orientation or approach to task; one that encourages openness, flexibility, and process over performance) throughout discussions in her workshops. Other practitioners may bridge-in to their activities by asking their group how they play, or what the term "play" means to them. Practitioners may then use this discussion as a way to unfold a working understanding of play for their purposes.

Second, play ambivalence may be tied to the playspace. That is, students may express ambivalence if they do not feel safe enough to engage with their own confusion, vulnerability, and 
Volume 28, 2018

http://journals.sfu.ca/cjsdw

insecurities, especially since playful activities often require a mixture of co-creation, agency, autonomy, and empowerment. One approach practitioners may take is to include students in the creation of playspaces, by engaging them in developing guidelines for participation, and via continual reinforcement that they each play a role and have a responsibility in co-creating a space in which they feel safe; note, the word "safe" has different meaning for everyone. Brittany will often explore the meaning of "safe" with students, and suggest that safe does not always mean "comfortable." Instead, she asks how everyone can contribute to co-creating a space in which everyone can preserve their dignity and engage with their discomfort productively. At the same time, students should be encouraged to participate-or not-to the extent that they wish to help them feel like the playspace is their own and can thus be manipulated and altered to feel personal.

Finally, although writing is central to academic pursuits, it is often discussed as a set of transparent, transferable skills that one should be able to "just figure out" (Lea \& Street, 1998). In this view, challenges with writing are framed as student deficits (Badenhorst et al., 2012). This view, coupled with "crisis control" models of writing development (Aitchison \& Lee, 2006, p. 270) and pedagogies of student-writing-as-problem or othering (Badenhorst, et al., 2012), may influence play ambivalence, especially as it relates to the use of play in graduate writing development. Practitioners may choose to unpack these views of writing (and play) in conversation with other broader theories of writing, such as that of writing as a product and process situated in a social and rhetorical landscape (that is, a socio-rhetorical view of writing—see Paré, 2009), which in turn may strengthen the playspace and efforts to incorporate play. Relatedly, framing play from a "growth" perspective (for example, play as an incremental process that develops over time, and sometimes not in a straightforward manner) rather than a "fixed" perspective (for example, play as a talent, as something you either have or do not) may support efforts to create a playspace that is beneficial. But by the same token, practitioners must also model these perspectives for students. Overall, future research may further consider these and other ways in which students resist or are ambivalent towards play.

In this paper, we suggested that researchers and educators interested in utilising playful methods would benefit from a shared understanding of three interrelated concepts. First, we offered a working definition of play. Then, we brought forward the notion of playspace, as well as implicit theories of intelligence (a.k.a. "mindset"). In addition, we offered some concluding remarks about what we call play ambivalence, which may be related in part to the three concepts 
underscored in this article. Though not a focus of the article, we also located ourselves as graduate writers and traced one layer of the palimpsest by offering a glimpse at the activities we used to generate ideas for this paper. In a way, by doing so, we traced an aspect of ourselves as graduate writers and burgeoning researchers, highlighting briefly and fleetingly the selves that co-authored this paper before disappearing again behind the curtain of what we hope will be the beginning of a blossoming conversation about play and graduate writing development.

\section{Endnotes}

1. Correspondence may be addressed to Brittany.Amell@Carleton.ca.

2. And though we tend to use the term "writing" rather than "writing/research" throughout this paper, this is how we understand "writing" - in addition to the processes and products required of graduate students to participate fully in their programs.

3. A piece of writing material on which vestiges of an earlier text are either fully or partially visible (Baldick, 2004).

\section{Acknowledgments}

We thank Lisa Armstrong, Alicia Massie, Dr. Cecile Badenhorst, Janna Klostermann and our four reviewers for their insightful critiques and suggestions on earlier drafts of this manuscript.

\section{Appendix: Question Stems}

Adapted by Brittany Amell from Blakeslee and Fleisher (2007), McTighe and Wiggins (2013), and Parkin (2009).

- How did __ come about? Why is this so?

_ What caused ___?

_ What are the effects of ___ ?

- How is __ connected to ___ ?

_ How might ___ help us to understand ___ ?

_ What does ___ reveal about___ ?

- How does ___ relate to ___ ?

- How is ___ applied to ___ ? 
Volume 28, 2018

http://journals.sfu.ca/cjsdw

_ How might ___ help us to ___ ?

_ How might ___ look from ___ 's perspective?

_ How are our views about ___ shaped by ____?

_ In what way is ___ similar or different to ___ ?

- What is the relationship of ___ to ___ ?

_ What experiences do ___ have with ___ ?

- How is ___ defined in the literature?

- What happens when ___?

_ What are the salient features of ___ and what influenced them?

\section{References}

Aitchinson, A., Kamler, B., \& Lee, A. (2010). Why publishing pedagogies? In A. Aitchinson, B. Kamler, \& A. Lee (Eds.), Publishing pedagogies for the doctorate and beyond (pp. 1-11). New York, NY: Routledge.

Aitchison, C., \& Lee, A. (2006). Research writing: Problems and pedagogies. Teaching in higher education, 11(3), 265-278. doi:10.1080/13562510600680574

Amell, B. (2016). "The first [draft] was a lot of me ... but the second one is what they want": A multiple-case study of four indigenous students' experiences with academic writing (Unpublished doctoral dissertation). Carleton University: Ottawa, ON.

Badenhorst, C., Moloney, C., Rosales, J., \& Dyer, J. (2016). Thinking through play: "visual" approaches to post/graduate research writing. In C. Badenhorst \& C. Guerin (Eds.), Studies in writing: Research literacies and writing pedagogies for masters and doctoral writers (pp. 335-355). Leiden, NL: Brill.

Badenhorst, C., Moloney, C., Rosales, J., \& Dyer, J. (2012). Graduate research writing: A pedagogy of possibility. LEARNing Landscapes, 6(1), 63-80. Retrieved from: http://learninglandscapes.ca/index.php/learnland/article/view/576

Badenhorst, C., Moloney, C., Dyer, J., Rosales, J., \& Murray, M. (2015). Thinking creatively about research writing. In T. Lillis, K. Harrington, M. R. Lea, \& S. Mitchell, (Eds.) Working with academic literacies: Case studies towards transformative practice (pp.3-22). Fort Collins, Colorado \& Anderson, South Carolina: The WAC Clearinghouse \& Parlor Press. 
Volume 28, 2018

http://journals.sfu.ca/cjsdw

Baldick, C. (2004). Oxford concise dictionary of literary terms. Oxford: Oxford University Press.

Barnett, L. A. (2007). The nature of playfulness in young adults. Personality and Individual Differences, 43, 949-958. doi: 10.1016/j.paid.2007.02.018

Barnett, L. A. (2012). Playful people: Fun is in the mind of the beholder. Imagination, Cognition, and Personality, 31, 169-197. doi:10.2190/IC.31.3.c

Bartholomae, D. (1986). Inventing the university. Journal of Basic Writing, 5 (1), 4-23.

Bergen, D. (2015). Psychological approaches to the study of play. American Journal of Play, 7(3), 101-128.

Bird, A., \& Reese, E. (2008). Autobiographical memory in childhood and the development of a continuous self. In F. Sani (Ed.), Individual and collective self-continuity: Psychological perspectives (pp. 43-54). NY: Psychology Press.

Blackwell, L., Trzesniewski, K., \& Dweck, C. S. (2007). Implicit theories of intelligence predict achievement across an adolescent transition: A longitudinal study and an intervention. Child Development, 78(1), 246-263. doi:10.1111/j.1467-8624.2007.00995.x

Blakeslee, A. \& Fleisher, C. (2007). Becoming a writing researcher. Mahwah, New Jersey: Lawrence Erlbaum.

Cotterall, S. (2011). Doctoral students writing: Where's the pedagogy? Teaching in Higher Education, 16(4), 413-425. doi:10.1080/13562517.2011.560381

Crang, M. \& Thrift, N. J. (2000). Thinking space. New York: Routledge. doi:10.4324/9780203411148

Csikszentmihalyi, M. (1991). Flow: The psychology of optimal experience. New York, NY: HarperCollins.

Damasio, A. (2010). Self comes to mind: constructing the conscious brain. New York,

NY: Knopf Doubleday Publishing Group.

Davies Turner, M. \& Turner, J. (2015). Play and creativity in academic writing. In C. Badenhorst \& C. Guerin (Eds.), Studies in writing: Research literacies and writing pedagogies for masters and doctoral writers (pp. 356-370). Leiden, NL: Brill.

Downs, D., \& Wardle, E. (2007). Teaching about writing, righting misconceptions: (re)envisioning "first-year composition" as "introduction to writing studies". College Composition and Communication, 58(4), 552-584.

Dweck, C. S. (1999). Self-theories: Their role in motivation, personality, and development. Philadelphia: Psychology Press.

Dweck, C. S. (2007). The perils and promises of praise. Educational Leadership, 65(2), 34-39. 
Volume 28, 2018

http://journals.sfu.ca/cjsdw

Retrieved from: www.ascd.org/publications/educational-leadership/oct07/vol65/num02/The-

Perils-and-Promises-of-Praise.aspx

Dweck, C. S., Chiu, C. Y., \& Hong, Y. Y. (1995). Implicit theories and their role in judgements and reactions: A word from the two perspectives. Psychological Inquiry, 6(4), 267-285. doi: $10.1207 /$ s15327965pli0604_1

Dweck, C. S., \& Leggett, E. L. (1988). A social-cognitive approach to motivation and personality. Psychological Review, 95, 256-273. doi:10.1037/0033-295X.95.2.256

Fonteyn, M. E., Kuipers, B., \& Grobe, S. J. (1993). A description of think aloud method and protocol analysis. Qualitative Health Research, 3(4), 430-441. doi: 10.1177/104973239300300403

Glynn, M. A., \& Webster, J. (1992). The adult playfulness scale: An initial assessment. Psychological Reports, 71, 83-103. doi: 10.2466/PR0.71.5.83-103

Henderson, V., \& Dweck, C. S. (1990). Motivation and achievement. In S. S. Feldman \& G. R. Elliott (Eds.), At the threshold: The developing adolescent (pp. 308-329). Cambridge, MA: Harvard University Press.

Henricks, T. S. (2014). Play as self-realization: Toward a general theory of play. American Journal of Play, 6(2), 190-213.

Hubbard, P., \& Kitchin, R. (2011). Why key thinkers? In P. Hubbard \& R. Kitchin (Eds.), Key thinkers on space and place (pp. 2-17). Thousand Oaks, California: SAGE.

James, W. (1890). The principles of psychology. New York, NY: Holt.

Janks, H. (2012). The discipline and craft of academic writing: Building writing capacity in Institutions of Higher Education. Reading \& Writing 3(1), pp. 1-9. Retrived from: http://dx.doi.org/10.4102/rw.v3i1.25

Jazvac-Martek, M., Chen, S. \& McAlpine, A. (2011). Tracking the doctoral student experience over time: Cultivating agency in diverse spaces. In L. McAlpine \& C. Amundsen (Eds.), Doctoral Education: Research-Based Strategies for Doctoral Students, Supervisors and Administrators (pp.17-36). New York, NY: Springer.

Kamler, B. \& Thomson, P. (2006). Helping doctoral students write: Pedagogies for supervision. London: Routledge. doi:10.4324/9780203969816

Keefer, J. M. (2015). Experiencing doctoral liminality as a conceptual threshold and how supervisors can use it. Innovations in Education and Teaching International, 52(1), 17-28. doi:10.1080/14703297.2014.981839 
Volume 28, 2018

http://journals.sfu.ca/cjsdw

Kiley, M. (2009). Identifying threshold concepts and proposing strategies to support doctoral candidates. Innovations in Education and Teaching International, 46(3), 293-304. doi:10.1080/14703290903069001

Larrivee, B. (2000). Transforming teaching practice: Becoming the critically reflective teacher. Reflective Practice: International and Multidisciplinary Perspectives, 1(3), 293-307. doi: $10.1080 / 713693162$

LaRocque, E. (2015). Foreword: "Resist No Longer"-Reflections on resistance writing and teaching. In E. Coburn (Ed.), More will sing their way to freedom: Indigenous resistance and resurgence (pp.5-23). Winnipeg, Manitoba: Fernwood Publishing.

Lea, M., \& Street, B. (1998). Student writing in higher education: An academic literacies approach. Studies in Higher Education, 23(2), 157-172. doi:10.1080/03075079812331380364

Lillis, T., \& Scott, M. (2007). Defining academic literacies research: Issues of epistemology, ideology and strategy. Journal of Applied Linguistics, 4(1), 5-32. doi: 10.1558/japl.v4i1.5

Magnuson, C. D., \& Barnett, L. A. (2013). The playful advantage: How playfulness enhances coping with stress. Leisure Sciences, 35, 129-144. doi: 10.1080/01490400

Maher, D., Seaton, L., McMullen, C., Fitzgerald, T., Otsuji, E., \& Lee, A. (2008). 'Becoming and being writers': The experiences of doctoral students in writing groups. Studies in Continuing Education, 30(3), 263-275. doi: 10.1080/01580370802439870

McTighe, J., \& Wiggins, G. (2013). Essential questions: Opening doors to student understanding. Alexandria, Virginia: ASCD.

Melamed, E. (1985). Play and Playfulness in Women's Learning and Development (Unpublished doctoral dissertation). University of Toronto: Toronto, Canada.

Meyer, J. H. F., \& Land, R. (2006). Threshold concepts and troublesome knowledge: an introduction. In J.H.F. Meyer \& R. Land (Eds.), Overcoming barriers to student understanding: Threshold concepts and troublesome knowledge (pp. 3-18). London, UK: Routledge.

Meyer, P. (2012). Embodied learning at work: Making the mind-set shift from workplace to playspace. New Directions for Adult and Continuing Education, 2012(134), 25-32. doi:10.1002/ace.20013

Miller, B. (2013). Metaphor, writer's block, and the legend of zelda: A link to the writing process. In R. Colby, M.S.S. Johnson, \& R. Shultz Colby (Eds.), Rhetoric/composition/play through video games: Reshaping theory and practice of writing (pp.99-111). New York: Palgrave Macmillan. Moore, C., \& Barresi, J. (2013). Imagination and the Self. In P. E. Nathan, \& M. Taylor (Eds.), The 
Volume 28, 2018

http://journals.sfu.ca/cjsdw

Oxford Handbook of the Development of Imagination (pp.288-304). Oxford, UK: Oxford University Press.

Nagelhout, E., \& Rutz, C. (2004). Classroom spaces and writing instruction. Cresskill, N.J: Hampton Press.

O’Rourke, E., Haimovitz, K., Ballwebber, C., Dweck, C. S., \& Popovic, Z. (2014). Brain points: A growth mindset incentive structure boosts persistence in an educational game. Proceedings of the SIGCHI conference on human factors in computing systems, 3339-3348.

Paré, A. (2009). What we know about writing and why it matters. Compendium2: Writing, Teaching, and Learning in the University, 2(1). Retrived from:

https://ojs.library.dal.ca/C2/article/view/3720/3408

Paré, A. (2011). Speaking of writing: Supervisory feedback and the dissertation. In L. McAlpine \& C. Amundsen (Eds.), Doctoral education: Research-based strategies for doctoral students, supervisors and administrators (pp. 59-74). Dordrecht, NL: Springer Netherlands.

Parkin, S. (2009). Ivanic and the concept of "wrighting." In A. Carter, T. Lillis, \& S. Parkin (Eds.), Why Writing Matters (pp. 27-43). Philadelphia, USA: John Benjamins Publishing Company.

Peabody, M.A., \& Noyes, S. (2017). Reflective boot camp: Adapting LEGO® SERIOUS PLAY® in higher education. Reflective Practice 12(2), 232-243. doi: 10.1080/14623943.2016.1268117

Pratt, M.L. (1998). Arts of the contact zone. In V. Zamel \& R. Spack (Eds.). Negotiating academic literacies: Teaching and learning across languages and cultures (pp.171-198). Mahwah, N.J: Lawrence Erlbaum Associates.

Proyer, R. T. (2011). Being playful and smart? The relations of adult playfulness with psychometric and self-estimated intelligence and academic performance. Learning and Individual Differences, 21, 463-467. doi: 10.1016/j.lindif.2011.02.003

Proyer, R. T. (2012). Examining playfulness in adults: Testing its correlates with personality, positive psychological functioning, goal aspirations, and multi-methodically assessed ingenuity. Psychological Test and Assessment Modeling, 54, 103-127. doi: 10.5167/uzh-63532

Proyer, R. T. (2013). The well-being of playful adults: Adult playfulness, subjective well-being, physical well-being, and the pursuit of enjoyable activities. European Journal of Humor Research, 1, 84-98. doi: 10.5167/uzh-78008

Proyer, R. T., Ruch, W., \& Müller, L. (2010). Sense of humor among the elderly: Findings with the German version of the SHS. Zeitschrift für Gerontologie und Geriatrie, 43, 19-24. doi: 
Volume 28, 2018

http://journals.sfu.ca/cjsdw

10.1007/s00391-009-0082-0

Qian, X. L., \& Yarnal, C. (2011). The role of playfulness in the leisure stress coping process among emerging adults: An SEM analysis. Leisure/Loisir, 35, 191-209. doi:

10.1080/14927712.2011.578398

Savin-Baden, M. (2008). Learning spaces: Creating opportunities for knowledge creation in academic life. Berkshire, UK: Open University Press

Simmons, N., \& Daley, S. (2013). The art of thinking: Using collage to stimulate scholarly work. Canadian Journal for the Scholarship of Teaching and Learning, 4(1), 1-11.

Schmidt, J. A., Shumow, L., \& Kackar-Cam, H. Z. (2016). Does the mindset intervention predict students' daily experience in classrooms? A comparison of seventh and ninth graders' trajectories. Journal of Youth and Adolescence, 46, 582-602.

Singer, D. G., \& Singer, J. L. (1990). The house of make-believe: Children's play and the developing imagination. Cambridge, MA: Harvard University Press.

Statler, M., Heracleous, L., \& Jacobs, C. D. (2011). Serious play as a practice of paradox. The Journal of Applied Behavioral Science, 47(2), 236-256. doi:10.1177/0021886311398453

Sutton-Smith, B. (1997). The ambiguity of play. Cambridge, MA: Harvard University Press.

Sutton-Smith, B. (2008). Play theory: A personal journey and new thoughts. American Journal of Play, 1, 80-123.

Sutton-Smith, B., \& Kelly-Byrne, D. (1984). The idealization of play. In P. K. Smith (Ed.), Play in animals and humans (305-321). Oxford, UK: Basil Blackwell Inc.

Tanis, D. J. (2012). Exploring play/playfulness and learning in the adult and higher education classroom (Unpublished doctoral dissertation). Pennsylvania State University.

Trafford, V., \& Leshem, S. (2009). Doctorateness as a threshold concept. Innovations in Education and Teaching International, 46(3), 305-316. doi:10.1080/14703290903069027

Turner, V. W. (1982). From ritual to theatre: The human seriousness of play. New York City: Performing Arts Journal Publications.

van Leeuwen, L., \& Westwood, D. (2008). Adult play, psychology and design. Digital Creativity, 19(3), 153-161. doi:10.1080/14626260802312665

Vygotsky, L. S. (1978). Mind in society: The development of higher psychological processes. Cambridge, MA: Harvard University Press.

West, S. E., Hoff, E., \& Carlsson, I. (2016). Play and productivity: Enhancing the creative climate at workplace meetings with play cues. American Journal of Play, 9(1), 71-86. 
Volume 28, 2018

http://journals.sfu.ca/cjsdw

Yu, P., Chen, J.-J., \& Lin, Y.-T. (2007). Is playfulness a benefit to work? Empirical evidence of professionals in Taiwan. International Journal of Technology Management, 39, 412-429. doi: 10.1504/IJTM.2007.013503 